\title{
Influence of Cardio-Respiratory Fitness on Physical Performance in Elite Youth Soccer
}

\author{
Greg Doncaster*1, John Iga ${ }^{3}$ and Viswanath Unnithan ${ }^{2}$ \\ ${ }^{1}$ Department of Sport \& Physical Activity, Edge Hill University, UK \\ ${ }^{2}$ Institute of Clinical Exercise and Health Science, University of the West of Scotland, UK \\ ${ }^{3}$ Performance Services, Huddersfield Town FC, UK
}

Submission: June 20, 2018; Published: July 12, 2018

*Corresponding author: Greg Doncaster, Department of Sport \& Physical Activity, Edge Hill University, UK, Tel: 01695 584151;

Email: doncasg@edgehill.ac.uk

\section{Abstract}

The purpose of this study was to assess the relationship between: Peak oxygen uptake $\left(\mathrm{VO}_{2 \max }\right)$ and running economy (RE) with physical measures associated with elite youth soccer performance obtained during soccer match-play. Seventeen highly trained youth soccer players (age: $13.3 \pm 0.4 \mathrm{y}$ ) volunteered to participate. Initially player's ventilatory threshold (VT) and $\mathrm{VO}_{2 \max }$ was established using a treadmill protocol. On the subsequent visit, players ran for $4 \mathrm{~min}$, at three different speeds ( $8 \mathrm{~km} / \mathrm{h}, 80 \% \mathrm{VT}$ and $95 \% \mathrm{VT}$ ). Physical soccer-based performance was assessed using a maximal Yo-Yo IR1 and via Global positioning systems (GPS) derived variables obtained during three, 2x20min, $11 \mathrm{v} 11$ soccer matches. Partial correlations revealed significant relationships between relative $\mathrm{VO}_{2 \max }$ and measures of physical soccer performance $(\mathrm{r}=0.54-0.88)$. Moreover, measures of ventilatory equivalent $\left(\mathrm{V}_{\mathrm{E}} \mathrm{VO}_{2}\right)$, a determinant of $\mathrm{RE}$, at all sub-maximal exercise intensities were inversely related to the volume (m) and percentage (\%) of very high intensity activities. Current findings emphasise the need for high levels of cardio-respiratory fitness in high level youth soccer players, with superior levels of fitness being associated with a greater amount of high and very high intensity activity during soccer match-play.

Keywords: Aerobic Capacity; Running Economy; Youth Soccer; Team Sports; Respiratory Fatigue

Abbrevations: RE: Running Economy; VT: Ventilatory Threshold; GPS: Global Positioning Systems; RER: Respiratory Exchange Ratio; GET: Gaseous Exchange Threshold

\section{Introduction}

Soccer is described as a high-intensity intermittent sport, with elite players demonstrating a superior ability to perform high-intensity activities during competitive match-play in both adult [1] and youth [2] soccer. During match-play, however, low intensity activities account for the majority of an individual's physical performance, at all levels of competition [3,4]. As a result, the aerobic energy system is the predominant source of energy expenditure during soccer match-play, accounting for more than $90 \%$ of the total energy demand [3]. Furthermore, research suggests that youth populations are better equipped to use oxidative energy pathways, when compared to adult populations, resulting in a greater utilisation of aerobic energy pathways for the same relative exercise intensity and reduced level of metabolic acidosis [5,6].Consequently, determinants of cardio-respiratory (aerobic) fitness may have a significant impact upon youth players' physical performance during soccer match-play and, in particular, their ability to perform repeated bouts of high intensity activities. Superior levels of maximum oxygen consumption $\left(\mathrm{VO}_{2 \max }\right)$ will, theoretically, enable players to work at a higher intensity during soccer match-play, for a lower relative energy cost than those with inferior levels of $\mathrm{VO}_{2 \max }$ [1]. Furthermore, soccer-specific endurance capacity has been shown to be an essential characteristic for youth players aiming to progress to elite adult status $[7,8]$. Despite this, the impact of enhanced aerobic capacity $\left(\mathrm{VO}_{2 \max }\right)$ on physical soccer performance has produced equivocal results. With some studies reporting positive relationships between $\mathrm{VO}_{2 \max }$ and physical performance measures associated with soccer match-play [9], while others have reported no relationship between $\mathrm{VO}_{2 \max }$ and measures of physical performance [10]. Rebelo et al. [10] reported that the high intensity running performed during a competitive match, in adult soccer was closely related to a player's $\mathrm{VO}_{2 \max }(\mathrm{r}=0.81)$. Despite the equivocal nature of the relationship between $\mathrm{VO}_{2 \max }$ and markers of match-play, the attainment of 
measures of physical performance in situ (during match-play) are lacking. Such measures will enhance the ecological validity and application of measures obtained from both laboratory and field tests, when used to assess team sports performance. Thus, aiding in the assessment of the relationship between cardiorespiratory fitness and team sports performance, with further implications for training practices as well as talent identification and development.

Large components of competitive soccer match-play are comprised of low intensity activity [3], as a result, superior levels of running economy (RE) may result in the preservation of energy during periods of low-intensity exercise. Work by Ziogas et al. [11] revealed that players who competed in a higher division had a superior RE when running at $12 \mathrm{~km} / \mathrm{h}$ ${ }^{1}$ (Division $\mathrm{A}=75.8 \%$, Division $\mathrm{B}=78.7 \%$, Division $\mathrm{C}=80.5 \%$ V02max). This demonstrates that measures of RE (expressed as a percentage of V02max) may be able to discriminate between playing level, but provides no indication to the extent to which RE may impact upon physical performance during soccer matchplay. Moreover, Stroyer et al. [4] assessed the RE and the activity patterns of young soccer players during match-play, however the relationship between the two measures was not reported. As a result, the contribution that RE and determinants of RE may play with regard to effective soccer-match play, particularly in youth populations, where there is an increased reliance upon aerobic energy production $[5,12]$, requires investigating. Furthermore, due to the intensified [13], exhaustive and intermittent [1,3] nature of soccer, other determinants of RE may also provide an indication toward an individual's ability to perform highintensity activities during soccer match-play. Di Paco et al. [14] demonstrated an improved ventilatory efficiency for a given exercise intensity in soccer players of a superior fitness level. Consequently, the purpose of this study was to determine the relationship between: VO2max, RE and determinants of $\mathrm{RE}$, and physical measures associated with elite youth soccer performance during soccer match-play within a group of highly trained youth soccer players. It was hypothesized that superior measures of VO2max, RE and parameters of RE would be significantly correlated with physical performance measures during elite youth soccer match-play.

\section{Methods}

Seventeen highly trained youth soccer players aged between 12 and 14 years volunteered to participate in this study. All participants were outfield players ( 5 defenders, 6 midfielders and 6 attackers) from the same Category One, Premier League Soccer Academy. Prior to the commencement of the study, all players completed medical health questionnaires and training history questionnaires. Table 1 illustrates all anthropometric and screening measures. Maturity status was quantified using self-assessment, Tanner Stage method and maturity offset [15]. Players and their parents were informed about all procedures and requirements involved in the study before providing written informed consent and assent from parents and participants, respectively. Ethical approval was granted from the local university ethics committee prior to the commencement of the study. Data collection was conducted over a three-week period at the beginning of a competitive season (pre-season). During this period, anthropometric measurements as well as laboratory and field tests were conducted. The players visited the laboratory on 2 separate occasions, they then performed a field test and were involved in 3 sterile (same playing surface, pitch dimensions and including the same composition of players in the same positions) 11 v 11 matches. Goal keepers were excluded from the analysis due to the incomparable match demands with outfield players. Furthermore, while two teams of 10 outfield players equates to 20 potential participants, 3 of the players (despite taking part in the training matches) chose not to participate in the study, thus leaving a sample of 17 participants. During the first visit, players performed an incremental, ramp treadmill protocol for the assessment of players' gaseous exchange threshold (GET) and $\mathrm{VO}_{2 \max }$. Players returned to the laboratory for a second time, following a minimum of 24 hours of recovery. On the second visit, players were required to run for $4 \mathrm{~min}$, at progressive sub-maximal speeds $(8 \mathrm{~km} / \mathrm{h}, 80 \% \mathrm{GET}$ and $95 \% \mathrm{GET})$, with 2 min passive recovery between speed increments. Players then completed the field test and 3 sterile $11 \mathrm{v} 11$ matches over the following 2 weeks with a minimum of 48 hours between each test. All laboratory and field testing were completed at the same time of day ( \pm 2 hours), with room temperature, humidity and pressure corresponding to $20.5 \pm 1.5^{\circ} \mathrm{C}, 61.0 \pm 1.4 \%$ and $1016 \pm$ $3 \mathrm{mmHg}$ respectively, for laboratory testing.

Table 1: Anthropometric and screening measures.

\begin{tabular}{|c|c|c|}
\hline Variable & $\begin{array}{c}\text { Mean } \pm \text { Standard } \\
\text { Deviation }\end{array}$ & $\begin{array}{c}\text { 95\% Confidence } \\
\text { Intervals }\end{array}$ \\
\hline Age (y) & $13.3 \pm 0.4$ & $13.1-13.5$ \\
\hline Stature (m) & $1.59 \pm 0.11$ & $1.54-1.64$ \\
\hline Body Mass (kg) & $48.9 \pm 10.1$ & $43.9-53.9$ \\
\hline Maturity Offset (y) & $-0.8 \pm 0.9$ & -1.2 to -0.3 \\
\hline$\Sigma$ 4 Skinfolds (mm) & $30.7 \pm 5.1$ & $28.3-33.1$ \\
\hline Tanner Stage & $3 \pm 1$ & $2.4-5.3$ \\
\hline Training Years (y) & $4.4 \pm 2.1$ & $11.3-13.5$ \\
\hline $\begin{array}{c}\text { Training Hours } \\
\text { (hrs.p.week) }\end{array}$ & $12.4 \pm 2.3$ & \\
\hline
\end{tabular}

Upon arrival to the laboratory and following the necessary screening procedures, participants were fitted with a Polar Heart rate monitor (Polar Electro, Kempele, Finland) and facemask (Hans Rudolph, Hans Rudolph, Kansas City, USA), which was connected to an online gas analysis system (Cortex Meta Max 3B, Cortex Biophysik GmbH, Leipzig, Germany). The online gas analyser was calibrated prior to each visit according to the manufacturer's instructions, using a known gas concentration and a 3-L syringe for manual volume calibration of the ventilation sensors. Following a standardised $10 \mathrm{~min}$ warm up and a full 
description of the test and safety procedures, participants began to run at a speed of $8 \mathrm{~km} / \mathrm{h}$ at a $1 \%$ incline [16] on a motorised treadmill (HP Cosmos, Pulsar, Sportgerate GmbH, Nussdorf, Germany). The speed of the treadmill was increased by $1 \mathrm{~km} / \mathrm{h}$ every two minutes, this continued until participants reached $90 \%$ of their age predicted heart rate max (207-(0.7 x age)) [17]. At this point, the treadmill speed remained constant whilst the incline of the treadmill was increased by $1 \%$ every minute until volitional exhaustion; this procedure was employed to avoid over-striding and potential early termination and inaccurate assessment of participant's $\mathrm{VO}_{2 \max }$. This method has been successfully used before to elicit $\mathrm{VO}_{2 \max }$ during treadmill running in young athletes [18]. Rolling $15 \mathrm{sec}$ averages were calculated for the final minute of the test to verify if a plateau was present, with the highest $15 \mathrm{sec}$ average during the test being regarded as $\mathrm{VO}_{2 \max }$ [19]. It is well documented that children can exercise to exhaustion without exhibiting a $\mathrm{VO}_{2}$ plateau [20]. Nevertheless, test criteria for a maximal effort, were the achievement of at least two of the following three performance values: 1) respiratory exchange ratio (RER) above $1.00,2$ ) plateau in $\mathrm{VO}_{2}$ despite an increasing speed $\left.\left(<2 \mathrm{~mL} \cdot \mathrm{kg}^{-1} \cdot \mathrm{min}^{-1} ; 10\right) 3\right)$ heart rate \pm 10 beats/min of age predicted maximal heart rate [20]. The $\mathrm{VO}_{2 \max }$ protocol resulted in $100 \%$ percent of the participants reaching an RER value of greater than 1.00 and a heart rate value within \pm 10 beats $/ \mathrm{min}$ of age predicted maximal heart rate, while $88 \%$ of the participants presented a plateau in $\mathrm{VO}_{2}$ despite an increase in speed. As all players did fulfil two of the stated criteria, the term $\mathrm{VO}_{2 \max }$ was preferred [21].

The gaseous exchange threshold (GET) was identified using the V-slope method ( $\mathrm{V}_{\mathrm{E}}$ (ordinate), $\mathrm{VO}_{2}$ (abscissa). Two regression lines were created based upon the relationship between $\mathrm{VCO}_{2}$ and $\mathrm{VO}_{2}$. The intercept point between the two regression lines was then visually identified, with the $\mathrm{VO}_{2}$ value at the intercept (GETS) being extrapolated to the abscissa [22]. To identify the speed at GET, a regression equation was formulated for $\mathrm{VO}_{2}$ and running velocity, for each individual. The individual's $\mathrm{VO}_{2}$ at GET was then inputted into the individual's respective regression equation to calculate the running velocity at GET. The V-slope method has been shown to be a viable and reliable method for detecting and identifying the gaseous exchange threshold in children [23]. The GET was assessed by two individual researchers (experienced in the detection of GET), demonstrating 82\% agreement (14 out of 17). For the remaining three participants, a third researcher was approached to verify the GET. Following this test, running velocities corresponding to $80 \%$ GET and $95 \%$ GET were calculated for the assessment of running economy. On the subsequent visit to the laboratory, and following a minimum of 24 hours recovery, participants' RE was assessed at three progressive sub-maximal intensities (one absolute: $8 \mathrm{~km} / \mathrm{h}$ and two relatives: $80 \%$ GET and 95\% GET exercise intensities), with 2 min passive recovery between each intensity. Prior to testing, participants were fitted with a Polar Heart rate monitor and face-mask, which was connected to a pre-calibrated online gas analysis system. Following a standardised 10 min warm-up and a full description of the test procedures, participants began to run at the lowest exercise intensity (either $8 \mathrm{~km} /$ hour the running velocity equivalent to $80 \% \mathrm{GET}$ ), with the gradient of the treadmill set at 1\% [16]. Participants ran at this speed for 4 min, ensuring that a steady state was maintained for the final minute [21]. A 2 min passive recovery was then permitted, in which participants' heart rate recovered to pre-exercise levels. Pilot testing demonstrated that a $2 \mathrm{~min}$ passive recovery was shown to provide sufficient time for players to recover to resting heart rate levels, ensuring there were no ensuing effects on the subsequent exercise bouts. During this recovery period, the treadmill speed was increased to the next progressive speed (higher intensity of $8 \mathrm{~km} / \mathrm{h}^{-1}$ or $80 \%$ GET). Again, participants exercised at this speed for $4 \mathrm{~min}$, attaining a steady state, before undertaking a further $2 \mathrm{~min}$ recovery. Following the final $2 \mathrm{~min}$ of passive recovery, participants completed another $4 \mathrm{~min}$ period of sub-maximal running at the highest intensity (95\% GET).

Extraction of the appropriate measures for assessing $\mathrm{RE}$ included applying rolling $15 \mathrm{sec}$ averages for the final minute of each sub-maximal exercise intensity to ensure that a steady state had been attained. It has been shown that male youth populations will attain a steady state following $3 \mathrm{~min}$ of sub-maximal exercise [23]. Current results revealed that all participants $(100 \%)$ attained a steady state $\left(<2 \mathrm{~mL} \bullet \mathrm{kg}^{-1} \bullet \mathrm{min}^{-1}\right.$ (10), in the final minute of exercise) for each sub-maximal exercise intensity. Following the identification of a steady state, $\mathrm{RE}$ was defined as the average VO2 during the final minute of each exercise bout [21]. Relative oxygen consumption (VO2) was obtained for each exercise intensity as well as determinants of RE: minute ventilation (VE) and ventilatory equivalent (VEVO2). For the Yo-Yo IR1 test, cones were placed $20 \mathrm{~m}$ apart, with a $5 \mathrm{~m}$ recovery zone marked out at one end. The Yo-Yo IR1 test requires participants to run $2 \times 20 \mathrm{~m}$ shuttle runs at increasing speeds, interspersed with 10 seconds of active recovery. The pace of the test was controlled by audio signals emitted from a CD player (Sony CFD-V7, Sony, Tokyo, Japan). For the maximal Yo-Yo IR1 test, players were required to run until volitional termination of the test or, when they have twice failed to meet the designated cones in time with the audio signal, at which point they are removed from the test. The test score is the distance covered at the point they withdraw from the test. All players had previous experience of completing the Yo-Yo IR1 test and were therefore familiarised to the testing. During the test, players were allowed to consume fluids ad libitum. Previous evidence supports the use of the Yo-Yo IR1 test as a valid measure of soccer-specific fitness, particularly within youth populations [24].

For the assessment of participants' performance during soccer match-play, three separate, sterile (controlled, replicable and include the same composition of players in the same positions) $11 \mathrm{v} 11$ matches were conducted and analysed using $10 \mathrm{~Hz}$ GPS (Catapult, Melbourne, Australia) and Polar Heart rate monitors. Each match was conducted on the same third generation outdoor artificial pitch with the same pitch 
dimensions utilised within competitive match-play within this population $(90 \times 50 \mathrm{~m})$ and at the same time of day. Matches were comprised of $2 \times 20 \mathrm{~min}$ halves with a $5 \mathrm{~min}$ rest interval between halves. The composition of the teams and positions remained the same for all three matches and each participant was assigned their own GPS for all matches. Matches were performed on three separate occasions with a minimum of $24 \mathrm{hrs}$ between matches.

Following each match, the GPS data was downloaded and analysed using Catapult Software (Catapult, Melbourne, Australia) and specially designed Microsoft Excel spreadsheets. Following this, an average of the 3 games was calculated for each player for each variable. Data was recorded for the whole match, each $20 \mathrm{~min}$ half and into successive $5 \mathrm{~min}$ epochs (e.g. 0-5 min, $1-6 \mathrm{~min}, 2-7 \mathrm{~min}, 3-8 \mathrm{~min}$, etc), to establish and quantify the peak $5 \mathrm{~min}$ epoch, the subsequent $5 \mathrm{~min}$ epoch to the peak $5 \mathrm{~min}$ epoch and the mean of the cumulative $5 \mathrm{~min}$ epochs throughout the match. These were then averaged over the 3 sterile matches. Previous research has used discrete $5 \mathrm{~min}$ epochs (0-5min, 5-10 min, etc.) to identify the peak $5 \mathrm{~min}$ interval during soccer match-play [25]. However, the adoption of such criteria may result in missing the true peak $5 \mathrm{~min}$ epoch, as this may occur between the pre-determined, discrete $5 \mathrm{~min}$ epochs. Consequently, matches were analysed using successive $5 \mathrm{~min}$ epochs (0-5min, $1-6 \mathrm{~min}, 2-7 \mathrm{~min}$, etc.) for the identification of the most intense $5 \mathrm{~min}$ epoch. Information recorded included total distance (TD), metres per $\min (\mathrm{m} / \mathrm{min})$, relative high speed running distance metres (HSR), relative high speed efforts (HSReff), and relative very high speed running distance metres (VHSR), relative very high speed efforts (VHSReff) and relative sprint distance metres (S). Relative HSR running was regarded as distance covered above $50 \%$ of maximal linear velocity, relative VHSR was regarded as any distance covered above $70 \%$ of maximal linear velocity and relative Sprint as anything above $90 \%$ maximal linear velocity. The same thresholds were used for HSReff and VHSReff and an effort was regarded as any occurrence when such a speed was attained and sustained for greater than $0.2 \mathrm{~s}$. Maximal velocity was defined as the maximal velocity obtained during a $20 \mathrm{~m}$ sprint from a standing start and obtained from the respective GPS devices which the player would wear during the competitive and sterile soccer matches.

A Shapiro Wilks test found the data to be normally distributed; therefore parametric statistical calculations were applied. Partial correlations, controlling for maturation, were performed on the whole sample to assess the relationship between measures of cardio-respiratory fitness and physical soccer-based measures. To aid interpretation of the results, confidence intervals (90\%) for correlations were calculated and the magnitude of the correlations were determined using the modified scale by Hopkins [26] $(\mathrm{r}<0.1$, trivial; 0.1-0.3, small; $0.3-0.5$, moderate; $0.5-0.7$, large; $0.7-0.9$, very large; $>0.9$, nearly perfect; and 1 perfect).All statistical analysis was performed using SPSS version 21.0 (IBM SPSS statistics for Windows, IBM, Armonk, New York) and Microsoft Excel (Microsoft Excel 2013, Microsoft, Redmond, Washington) with the level of significance (alpha) set at 0.05 .

\section{Results}

Partial correlations revealed significant relationships between $\mathrm{VO}_{2 \max }\left(\mathrm{mL} \cdot \mathrm{kg}^{-1} \bullet \mathrm{min}^{-1}\right)$ and measures associated with physical soccer performance $(r=0.54-0.88)$, while measures of velocity at GET were only shown to be related to total distance $(r=0.51, \mathrm{P}<0.05)$ and VHSR $(r=0.51, \mathrm{P}<0.05)$. Only $\% \mathrm{VO}_{2 \max }$ at an absolute sub-maximal intensity of $8 \mathrm{~km} / \mathrm{h}$ revealed significant inverse correlations with TD $(r=-0.58, \mathrm{P}<0.05)$ and the volume $(r=-0.65, \mathrm{P}<0.05)$ and percentage of HSR during soccer matchplay $(r=-0.61, \mathrm{P}<0.05)$ as well as the number of HSR $(r=-0.58$, $\mathrm{P}<0.05)$ and VHSR $(r=-0.56, \mathrm{P}<0.05)$ efforts. With regards to measures and determinants of RE, only $\mathrm{V}_{\mathrm{E}} \mathrm{VO}_{2}$ at all sub-maximal exercise intensities were inversely related to the volume (m) and percentage (\%) of VHSR performed during the sterile soccer matches as well as the number of VHSR efforts (Table 2). Partial correlations between GPS derived variables, obtained during players' most intense $5 \mathrm{~min}$ period of match-play (i.e. peak 5min epochs) and relative $\mathrm{VO}_{2 \max }$ revealed no relationships, while velocity at GET was shown to be significantly related to measures of high intensity activity during players' peak $5 \mathrm{~min}$ epochs. However, partial correlations with the same GPS derived variables and relative $\mathrm{VO}_{2 \max }\left(\mathrm{mL} \bullet \mathrm{kg}^{-1} \bullet \mathrm{min}^{-1}\right)$ for the average $5 \mathrm{~min}$ epochs (the mean average of the cumulative $5 \mathrm{~min}$ epoch throughout match-play) were all significantly related. With regards to measures of running economy, again, only $\mathrm{V}_{\mathrm{E}} \mathrm{VO}_{2}$ at all sub-maximal exercise intensities were inversely related to the volume (m), percentage (\%) and efforts for VHSR, within the average $5 \mathrm{~min}$ epochs (Table 3 ).

Table 2: Partial correlations between GPS derived measures of soccer match-play and measures of cardio-respiratory fitness ( $r$ values).

\begin{tabular}{|c|c|c|c|c|c|c|c|c|}
\hline & \multicolumn{8}{|c|}{ Measures of Physical Soccer Performance } \\
\hline & Max Yo-Yo & TD (m) & HSR (m) & VHSR (m) & HSR (\%) & VHSR (\%) & HSR efforts & VHSR efforts \\
\hline Yo-Yo IR1 & - & $* 0.63$ & $* 0.64$ & $* 0.59$ & $* 0.61$ & ${ }^{*} 0.57$ & $* 0.60$ & $* 0.63$ \\
\hline $\mathrm{VO}_{2 \max }\left(\mathrm{mL} \cdot \mathrm{kg}^{-1} \bullet \mathrm{min}^{1}\right)$ & $* 0.88$ & $* 0.59$ & $* 0.73$ & $* 0.57$ & $* 0.70$ & $* 0.54$ & $* 0.74$ & $* 0.62$ \\
\hline Velocity at GET $(\mathrm{km} / \mathrm{h})$ & 0.48 & $* 0.51$ & 0.39 & $* 0.51$ & 0.33 & 0.49 & 0.28 & 0.44 \\
\hline $\mathrm{V}_{\mathrm{E}} \mathrm{VO}_{2} @ 8 \mathrm{~km} / \mathrm{h}$ & -0.49 & -0.39 & -0.38 & $*_{-}-0.69$ & -0.34 & $*-0.66$ & -0.33 & $*_{-}-0.67$ \\
\hline RER @ 8km/h & -0.36 & $*-0.56$ & -0.18 & -0.48 & -0.42 & -0.20 & -0.07 & -0.41 \\
\hline$\% \mathrm{HR}_{\max } @ 8 \mathrm{~km} / \mathrm{h}$ & 0.20 & -0.19 & -0.27 & 0.02 & -0.24 & 0.03 & -0.23 & 0.00 \\
\hline
\end{tabular}


Journal of Physical Fitness, Medicine \& Treatment in Sports

\begin{tabular}{|c|c|c|c|c|c|c|c|c|}
\hline$\% \mathrm{VO}_{2 \max } @ 8 \mathrm{~km} / \mathrm{h}$ & -0.42 & $*_{-} 0.58$ & $*-0.65$ & -0.47 & $*-0.61$ & -0.47 & $*_{-}-0.58$ & $*_{-} 0.56$ \\
\hline $\mathrm{V}_{\mathrm{E}} \mathrm{VO}_{2} @ 80 \% \mathrm{GET}$ & -0.22 & -0.02 & -0.32 & $*_{-} 0.64$ & -0.36 & $*_{-} 0.64$ & -0.35 & $*_{-} 0.66$ \\
\hline RER @ 80\%GET & 0.25 & -0.02 & -0.14 & -0.33 & -0.15 & -0.29 & -0.10 & -0.26 \\
\hline$\% \mathrm{HR}_{\max } @ 80 \% \mathrm{GET}$ & 0.25 & -0.04 & 0.01 & 0.18 & 0.04 & 0.19 & -0.05 & 0.15 \\
\hline$\% \mathrm{VO}_{2 \max } @ 80 \% \mathrm{GET}$ & -0.25 & -0.39 & -0.38 & -0.07 & -0.36 & -0.06 & -0.37 & -0.18 \\
\hline $\mathrm{V}_{\mathrm{E}} \mathrm{VO}_{2} @ 95 \% \mathrm{GET}$ & -0.50 & -0.24 & -0.44 & $*_{-} 0.62$ & -0.46 & $*_{-} 0.61$ & -0.44 & $*-0.67$ \\
\hline RER @ 95\%GET & -0.13 & -0.20 & -0.13 & -0.20 & -0.11 & -0.14 & -0.08 & -0.14 \\
\hline$\% \mathrm{HR}_{\max } @ 95 \% \mathrm{GET}$ & 0.07 & 0.06 & 0.09 & 0.27 & 0.11 & 0.29 & 0.02 & 0.20 \\
\hline$\% \mathrm{VO}_{2 \max } @ 95 \% \mathrm{GET}$ & -0.30 & -0.49 & -0.46 & -0.06 & -0.42 & -0.03 & -0.49 & -0.15 \\
\hline
\end{tabular}

Note: $\mathrm{VO}_{2}=$ Maximal oxygen consumption; GET $=$ Gaseous exchange threshold; $\mathrm{V}_{\mathrm{E}} \mathrm{VO}_{2}=$ Ventilatory equivalent; $\mathrm{RER}=\mathrm{Respiratory}$ exchange ratio; $\% \mathrm{HR}_{\max }=$ percentage of maximum heart rate; TD = Total Distance; HSR = High speed running; VHSR; Very high-speed running. Partial correlations were controlled for using self-assessed Tanner Stage values, ${ }^{*}=$ significant correlation $(P<0.05)$.

Table 3: Partial correlations between GPS derived measures of soccer match-play, during a peak 5 min epoch and match average $5 \mathrm{~min}$ epoch, and measures of cardio-respiratory fitness ( $r$ values).

\begin{tabular}{|c|c|c|c|c|c|c|c|c|c|c|}
\hline & \multicolumn{5}{|c|}{ Peak 5min epoch } & \multicolumn{5}{|c|}{ Match averages for $5 \mathrm{~min}$ epochs } \\
\hline & $\begin{array}{l}\text { TD } \\
\text { (m) }\end{array}$ & $\begin{array}{l}\text { HSR } \\
(\mathrm{m})\end{array}$ & $\begin{array}{c}\text { VHSR } \\
\text { (m) }\end{array}$ & $\begin{array}{c}\text { HSR } \\
\text { efforts }\end{array}$ & $\begin{array}{l}\text { VHSR } \\
\text { efforts }\end{array}$ & $\begin{array}{l}\text { TD } \\
\text { (m) }\end{array}$ & $\begin{array}{l}\text { HSR } \\
(\mathrm{m})\end{array}$ & $\begin{array}{c}\text { VHSR } \\
\text { (m) }\end{array}$ & $\begin{array}{c}\text { HSR } \\
\text { efforts }\end{array}$ & $\begin{array}{l}\text { VHSR } \\
\text { efforts }\end{array}$ \\
\hline Yo-Yo IR1 & 0.22 & 0.41 & $* 0.53$ & 0.45 & $* 0.56$ & $* 0.59$ & $* 0.50$ & $* 0.53$ & 0.46 & $* 0.51$ \\
\hline $\mathrm{VO}_{2 \max }\left(\mathrm{mL}^{\prime} \mathrm{kg}^{-1} \cdot \mathrm{min}^{-1}\right)$ & 0.19 & 0.29 & 0.36 & 0.29 & 0.36 & $* 0.60$ & $* 0.56$ & $* 0.55$ & $* 0.51$ & $* 0.53$ \\
\hline Velocity at GET & 0.25 & $*_{0}^{*} 0.58$ & $* 0.55$ & $* 0.60$ & $* 0.57$ & 0.38 & 0.29 & 0.35 & 0.26 & 0.34 \\
\hline $\mathrm{V}_{\mathrm{E}} \mathrm{VO}_{2} @ 8 \mathrm{~km} / \mathrm{h}$ & -0.38 & -0.48 & -0.38 & $*_{-0.62}$ & -0.48 & -0.26 & $*_{-}-0.51$ & $*_{-} 0.66$ & $*_{-}-0.51$ & $*_{-} 0.66$ \\
\hline RER @ 8km/h & $*_{-0.73}$ & $*_{-0.62}$ & $*_{-0.53}$ & $*_{-0.59}$ & $*-0.53$ & $*_{-0.55}$ & $*_{-0.56}$ & $*_{-0.64}$ & $*_{-}-0.50$ & $*_{-} 0.63$ \\
\hline$\% \mathrm{HR}_{\max } @ 8 \mathrm{~km} / \mathrm{h}$ & -0.11 & 0.11 & 0.14 & 0.20 & 0.17 & -0.25 & -0.04 & 0.12 & -0.04 & 0.13 \\
\hline$\% \mathrm{VO}_{2 \max } @ 8 \mathrm{~km} / \mathrm{h}$ & -0.24 & $*_{-} 0.57$ & -0.29 & $*-0.54$ & -0.29 & $*-0.52$ & $*-0.61$ & -0.47 & $*-0.60$ & -0.45 \\
\hline $\mathrm{V}_{\mathrm{E}} \mathrm{VO}_{2} @ 80 \% \mathrm{GET}$ & -0.23 & -0.27 & -0.08 & -0.43 & -0.19 & 0.02 & -0.48 & $*_{-} 0.61$ & -0.48 & $*_{-0.61}$ \\
\hline RER @ 80\%GET & -0.44 & -0.04 & 0.08 & -0.09 & 0.03 & -0.07 & -0.29 & -0.35 & -0.31 & -0.36 \\
\hline$\% \mathrm{HR}_{\max } @ 80 \% \mathrm{GET}$ & 0.05 & 0.31 & 0.32 & 0.39 & 0.35 & -0.05 & 0.02 & 0.19 & 0.01 & 0.20 \\
\hline$\% \mathrm{VO}_{2 \max } @ 80 \% \mathrm{GET}$ & -0.07 & 0.07 & 0.12 & 0.05 & 0.09 & -0.32 & -0.32 & -0.18 & -0.39 & -0.18 \\
\hline $\mathrm{V}_{\mathrm{E}} \mathrm{VO}_{2} @ 95 \% \mathrm{GET}$ & -0.26 & -0.35 & -0.12 & $*-0.51$ & -0.24 & -0.16 & $*_{-} 0.52$ & $*_{-} 0.61$ & $*_{-} 0.53$ & $*_{-} 0.60$ \\
\hline RER @ 95\%GET & -0.31 & 0.10 & 0.06 & 0.05 & 0.00 & -0.23 & -0.14 & -0.21 & -0.17 & -0.20 \\
\hline$\% \mathrm{HR}_{\max } @ 95 \% \mathrm{GET}$ & 0.20 & $* 0.50$ & 0.40 & 0.45 & 0.34 & 0.07 & 0.17 & 0.25 & 0.14 & 0.25 \\
\hline$\% \mathrm{VO}_{2 \max } @ 95 \% \mathrm{GET}$ & -0.09 & 0.16 & 0.11 & 0.21 & 0.13 & -0.46 & -0.27 & -0.07 & -0.28 & -0.06 \\
\hline
\end{tabular}

Note: $\mathrm{VO}_{2 \max }=$ Peak oxygen consumption; GET =Gaseous exchange threshold; $\mathrm{V}_{\mathrm{E}} \mathrm{VO}_{2}=$ Ventilatory equivalent; RER =Respiratory exchange ratio; $\% \mathrm{HR}_{\max }^{2 \max }=$ percentage of maximum heart rate; TD =Total Distance; HSR =High speed running; VHSR; Very high-speed running. Partial correlations were controlled for using self-assessed Tanner Stage values, ${ }^{*}=$ significant correlation $(P<0.05)$.

\section{Discussion}

The main findings of this study were 1) measures of relative $\mathrm{VO}_{2 \max }$ were significantly related to multiple measures of physical performance that are associated with superior soccer matchplay; 2) RE (expressed as $\% \mathrm{VO}_{2 \max }$ ) at an absolute intensity of $8 \mathrm{~km} / \mathrm{h}$ was significantly related to measures of high intensity activities performed duringyouth soccer match-play; and 3) while traditional measures of $\mathrm{RE}\left(\% \mathrm{VO}_{2 \max }\right)$, at relative intensities, were unrelated to measures of physical performance, a determinant of $\mathrm{RE}\left(\mathrm{V}_{\mathrm{E}} \mathrm{VO}_{2}\right)$, at all sub-maximal treadmill intensities (absolute and relative) was inversely related to measures of VHSR (metres, percentage and efforts), but not HSR, during competitive soccer match-play. To the authors' knowledge, this study is the first to assess the relationship between multiple measures of cardio- respiratory fitness in relation to physical soccer performance outcome measures, obtained during competitive soccer matchplay, in a group of highly trained youth players. Current findings support research that states measures of relative $\mathrm{VO}_{2 \max }(\mathrm{ml}$. $\mathrm{kg}^{-1} \cdot \mathrm{min}^{-1}$ ) and Yo-Yo IR1 performance are related to measures of physical performance during soccer match-play [27]. Present results found that $\mathrm{VO}_{2 \max }$ and measures of HSR (HSR metres: $\mathrm{r}=$ 0.73, $\mathrm{P}<0.05$; HSR\%: $\mathrm{r}=0.70, \mathrm{P}<0.05$ and HSR efforts: $\mathrm{r}=0.74$, $\mathrm{P}<0.05$ ) and VHSR (VHSR metres $\mathrm{r}=0.57, \mathrm{P}<0.05$; VHSR\%: $r$ $=0.54, \mathrm{P}<0.05$ and VHSR efforts: $\mathrm{r}=0.62, \mathrm{P}<0.05$ ), obtained during competitive soccer match-play were significantly related. Indeed, the contribution of aerobic energy supply has been shown to compensate for reductions in the energy supply from anaerobic metabolism during repeated sprints [28]. As a result, 
an enhanced ability to utilise oxidative energy pathways during high-intensity intermittent exercise may result in a greater accumulation, maintenance and frequency of high-intensity activities, thus maximising a players opportunity to compete effectively.

Similar to the present study, Krustrup et al. [9] reported significant relationships between measures of relative $\mathrm{VO}_{2 \max }$ and high-intensity distance covered during soccer match-play ( $\mathrm{r}$ $=0.81$ ), in elite female soccer players. Rebelo et al. [10], however, reported no significant relationships between measures of $\mathrm{VO}_{2 \max }$ and time spent in absolute speed zones during soccer-match play $(r=-0.13-0.25 ; P>0.05)$. However, it must be noted that Rebelo et al. [10] assessed players' physical performance during soccer match-play using time-motion analysis, one individual at a time and over a variety of games, thus exacerbating the issues of inter-match variability associated with assessing physical soccer performance during soccer match-play [29]. In the current study, all players were assessed simultaneously, using GPS analysis and during sterile soccer matches, in order to account for the complexities of variance involved in assessing physical performance during soccer match-play.

The current results demonstrate that traditional measures of RE (VO2 or $\% \mathrm{VO}_{2 \max }$ ) when exercising at an absolute intensity $(8 \mathrm{~km} / \mathrm{h})$ are related to measures of physical performance during soccer match-play. However, when RE is measured at a relative (80\%GET and $95 \% \mathrm{GET})$ exercise intensity, traditional measures of RE are not related to variables associated with superior physical soccer performance during match-play, within a group of highly trained youth soccer players. The use of RE as a measure to assess soccer-specific fitness is rarely adopted, this is probably due to the high-intensity, intermittent characteristics of soccer match-play. Despite this, research has advocated the need to improve soccer players' levels of RE via training [11]. In support of this, the current results demonstrated that a superior $\mathrm{RE}$ during an absolute intensity of $8 \mathrm{~km} / \mathrm{h}$ was significantly related to measures of HSR during soccer match-play. The current findings, however, may be a result of the different internal load which an absolute intensity of $8 \mathrm{~km} / \mathrm{h}$ equates to for each player, although such a finding may still be relevant as physical performance during competitive match-play does not account for players' relative fitness levels, maturity status or size (e.g. leg length) either. Consequently, the use of absolute sub-maximal intensities may be preferable when utilising traditional measures of RE to distinguish between physical performance during youth soccer match-play. Conversely, when relative exercise intensities ( $80 \%$ and $95 \%$ GET) were employed to assess RE, no relationships between traditional measures of $\mathrm{RE}$ and physical measures of performance during soccer matchplay were evident. When, however, alternative determinants of $\mathrm{RE}$ are evaluated with respect to their relationship with physical soccer performance different relationships emerge.
While results from the present study provide little support for relationships between measurements of RE and physical performance during soccer-match-play, a significant inverse relationship between $\mathrm{V}_{\mathrm{E}} \mathrm{VO}_{2}$ and measures associated with physical soccer performance was demonstrated. Work by Franch et al. [13] reported an average decrement of $11 \mathrm{~L} \cdot \mathrm{min}^{-1}$, in VE, while exercising at an intensity equivalent to $85 \% \mathrm{VO}_{2 \max }$, following 6 weeks of intensive endurance-based interval training. In addition, these same authors reported that other determinants of running economy such as: stride length, stride frequency, respiratory exchange ratio and muscle fibre distribution were unaltered. As a result, the responsiveness of $V_{E}$ to high intensity intermittent training, like that which is experienced during soccer, may have a positive impact on physical performance during soccer matchplay; with players at a higher level demonstrating an enhanced ventilatory efficiency $\left(\mathrm{V}_{\mathrm{E}} \mathrm{VO}_{2}\right)$ for a given exercise intensity [14] and therefore increased levels of physical performance during soccer match-play.

There were some limitations associated with this study. Firstly, correlation analyses do not infer causality. The 'thirdvariable problem' must be considered, as other measured or un-measured variables may affect the results. In an attempt to account for this, partial correlations were employed to control for the effects of maturation. Furthermore, the techniques used to assess maturity status within this study should also be considered. Indeed, the Tanner stage method of estimating maturity status does not provide information on the point at which a player entered a particular stage of maturation or how long an individual has been in a particular stage of maturation. Finally, relative thresholds were used to assess players' physical performance during soccer match-play. While this partly accounts for differences in growth and maturation, future research may look to examine the impact of such relationships when utilising both relative and absolute speed thresholds within the GPS analysis, when evaluating physical performance during soccer match-play. Such research will allow practitioners and researchers to establish the most appropriate methods for quantifying youth players' physical performance in both competition and training.

\section{Practical Implications}

The current paper looks to extend and improve upon existing research by providing an insight into the extent to which measures of cardio-respiratory fitness impact upon measures of physical performance during youth soccer matchplay. An improved understanding of the extent to which specific measures impact upon physical performance during youth soccer match-play will enable both sports practitioners and coaches to devise and implement training practices which are aligned to performance. Specifically, current results demonstrate that measures of relative $\mathrm{VO}_{2}$ peak are related to measures of physical performance. Therefore, measures of relative $\mathrm{VO}_{2}$ peak 
may be an appropriate means for assessing and monitoring youth players' physical development and player profiling, thus aiding in the identification of age appropriate training objectives for each player's individual development. Finally, the potential to delay the onset of respiratory muscle fatigue, during high intensity intermittent exercise provides interesting results. A delay in the onset of respiratory muscle fatigue may result in improvements in the amount of activity that can be performed at higher intensities, during soccer match-play. Consequently, sports practitioners may wish to promote the use of inspiratory muscle training as a concurrent training aid to supplement training outcomes.

\section{Conclusion}

Results of the present study reinforces evidence that suggests an enhanced $\mathrm{VO}_{2 \max }$ is associated with superior soccer performance, in a group of highly trained youth soccer players, with a superior aerobic capacity allowing for an improved maintenance of high intensity activities during soccer match-play. Strong correlations between $\mathrm{VO}_{2 \max }$ and physical performance during soccer match-play (high intensity activities) emphasises the need for high levels of aerobic capacity in highly trained youth soccer players. Moreover, while no relationships between traditional measures of RE and physical measures associated with soccer performance were evident, results provided potential support towards the implications of ventilatory efficiency $\left(\mathrm{V}_{\mathrm{E}} \mathrm{VO}_{2}\right)$ and its impact upon very high intensity activities (VHSR metres and efforts) during soccer match-play. However, further research should look to investigate the direct impact of ventilatory efficiency on measures associated with physical soccer performance during competitive match-play.

\section{Acknowledgement}

We would like to thank all the participants involved in the study for their committed participation. The authors would also like to thank the technical staff in the Faculty of Health Sciences at Staffordshire University for their excellent support. The authors would also like to declare that there was no provision of external funding or conflicts of interest in the completion of this study.

\section{References}

1. Mohr M, Krustrup P, Bangsbo J (2003) Match performance of highstandard soccer players with special reference to development of fatigue. Journal of Sports Science 21(7): 519-528.

2. Waldron M, Murphy A (2013) A comparison of physical abilities and match performance characteristics among elite and subelite under-14 soccer players. Pediatric Exercise Science 25(3): 423-434.

3. Iaia FM, Rampinini E, Bangsbo J (2009) High-intensity training in football. International Journal of Sports Physiology and Performance 4(3): 291-306.

4. Stroyer J, Hansen L, Klausen K (2004) Physiological profile and activity pattern of young soccer players during soccer match play. Medicine and Science in Sports and Exercise 36(1): 168-174.
5. Ratel S, Williams Oliver J, Armstrong N (2004) Effects of age and mode of exercise on power output profiles during repeated sprints. European Journal of Applied Physiology 92(1-2): 204-210.

6. Kappenstein J, Ferrauti A, Runkel H, Fernandez-Fernandez J, Muller $\mathrm{K}$, et al. (2013) Changes in phosphocreatine concentration of skeletal muscle during high-intensity intermittent exercise in children and adults. European Journal of Applied Physiology 113(11): 2769-2779.

7. Elferink-Gemser M, Huijgen B, Coelho-e-Silva M, Lemmink K, Visscher C (2012) The changing characteristics of talented soccer players - A decade of work in Groningen. Journal of Sports Science 30(15): 15811591.

8. Roescher CR, Elferink-Gemser MT, Huijgen B, Visscher C (2010) Soccer endurance development in professionals. International Journal of Sports Medicine 31(3): 174-179.

9. Krustrup P, Mohr M, Ellingsgaard H, Bangsbo J (2005) Physical demands during an elite female soccer game: Importance of training status. Medicine and Science in Sports and Exercise 37(7): 1242-1248.

10. Rebelo A, Brito J, Seabra A, Oliveira J, Krustrup P (2014) Physical match performance of youth football players in relation to physical capacity. European Journal of Sport Science 14(S1): S148-S156.

11. Ziogas GG, Patras KN, Stergiou N, Georgoulis A (2011) Velocity at lactate threshold and running economy must also be considered along with maximal oxygen uptake when testing elite soccer players during preseason. Journal of Strength and Conditioning Research 25(2): 414419.

12. Ratel S, Duche P, Williams C (2006) Muscle fatigue during high intensity exercise in children. Sports Med 36(12): 1031-1065.

13. Franch J, Madsen K, Djurhuus M, Pedersen P (1998) Improved running economy intensified training correlates with reduced ventilatory demands. Medicine and Science in Sports and Exercise 30(8): 12501256.

14. Di Paco, A Catapano, G Vagheggini, G Mazzoleni, S Levi, et al. (2014) Ventilatory response to exercise of elite soccer players. Multidisciplinary Respiratory Medicine 9(1): 20.

15. Mirwald R, Baxter-Jones A, Bailey D, Beunen G (2002) An assessment of maturity from anthropometric measurements. Medicine and Science in Sports and Exercise 34(4): 689-694.

16. Jones AM, Doust JH (1996) A 1\% treadmill grade most accurately reflects the energetic cost of outdoor running. Journal of Sports Science 14(4): 321-327.

17. Gellish RL, Goslin BR, Olson RE, McDonald A, Russi G, et al. (2007) Longitudinal modelling of the relationship between age and maximal heart rate. Medicine and Science in Sports and Exercise 39(5): 822829.

18. Williams CA, Carter H, Jones AM, Doust J (2001) Oxygen uptake kinetics during treadmill running in boys and men. Journal of Applied Physiology 90(5): 1700-1706.

19. Astorino T, Robergs R, Ghiasvand F, Marks D, Burns S (2000) Incidence of the oxygen plateau at VO2 peak during exercise testing to volitional exhaustion. Journal of Exercise Physiologyl Online 3(4): 1-12.

20. Armstrong N, Welsman J (1994) Assessment and interpretation of aerobic fitness in children and adolescents. Exercise Sports Science Review 22(1): 435-476.

21. Cooke C (2009) Maximal Oxygen Uptake, Economy and Efficiency. In: Eston R, Reilly T, (Eds); Kinanthropometry and Exercise Physiology Laboratory Manual: Tests, Procedures and Data ( $3^{\text {rd }}$ edn.); Routledge, London, pp. 174-212. 
22. Fawkner S, Armstrong N, Childs DJ, Welsman R (2002) Reliability of the visually identified ventilatory threshold and V-slope method in children. Pediatric Exercise Science 14(2): 181-192.

23. Unnithan VB, Timmons JA, Paton JY, Rowland T (1995) Physiologic correlates to running performance in pre-pubertal distance runners. International Journal of Sports Medicine 16(8): 528-533.

24. Bangsbo J, Iaia M, Krustrup P (2008) The Yo-Yo intermittent recovery test: A useful tool for evaluation of physical performance in intermittent sports. Sports Medicine 38(1): 37-51.

25. Bradley P, Noakes T (2013) Match running fluctuations in elite soccer: Indicative of fatigue, pacing or situational influences. Journal of Sports Science 31(15): 1627-1638.
26. Hopkins WG (2015) A Peer-Reviewed Journal and Site for Sport Research.

27. Karakoc B, Akalan C, Alemdaroglu U, Arslan E (2012) The relationship between the Yo-Yo tests, anaerobic performance and aerobic performance in young soccer players. Journal of Human Kinetics 35(1): 81-88.

28. Bogdanis G, Nevill M, Boobis L, Lakomy H (1996) Contribution of phosphocreatine and aerobic metabolism to energy supply during repeated sprint exercise. Journal of Applied Physiology 80(3): 876884.

29. Gregson W, Drust B, Atkinson G, Salvo VD (2010) Match-to-match variability of high speed activities in premier league soccer. International Journal of Sports Medicine 31(4): 237-242.

\section{Your next submission with Juniper Publishers will reach you the below assets}

- Quality Editorial service

- Swift Peer Review

- Reprints availability

- E-prints Service

- Manuscript Podcast for convenient understanding

- Global attainment for your research

- Manuscript accessibility in different formats ( Pdf, E-pub, Full Text, Audio)

- Unceasing customer service

Track the below URL for one-step submission https://juniperpublishers.com/online-submission.php 